\title{
Remesa social y diferenciación local en las migraciones laborales entre Colombia y Catalunya (Estado español). Un ejemplo etnográfico desde un municipio andino
}

Social Remittances and Local Differentiation in Labor
Migration between Colombia and Catalonia (Spain).
An Ethnographic Example from an Andean Town

Núria Morelló Calafell

Universitat de Barcelona

\section{RESUMEN}

El artículo analiza un programa de migración laboral y codesarrollo implementado en Colombia por empresas catalanas, como una experiencia de institucionalización migratoria. El programa fue objeto de investigación etnográfica entre los años 2012 y 2013, en Colombia y en varias comunidades hacia donde se movilizó mano de obra en el sector agrario europeo. El texto analiza la migración como recurso de movilidad social y geográfica, desde el significado político y social que esta adquiere en sociedades, localidades y grupos domésticos que permanecen activos en el país de origen.

Palabras clave: migración circular, codesarrollo, remesa social, diferenciación local.

\begin{abstract}
This article analyzes a labor migration and codevelopment program implemented in $\mathrm{Co}$ lombia by Catalan businesses as an attempt of migratory institutionalization. This program was the subject of ethnographic research conducted between 2012 and 2013 in Colombia and several communities of the European agricultural sector where the labour force was mobilized. The text analyzes migration as a resource for geographical and social mobility, and its social and political meaning in societies, localities, and domestic groups that remain active in the country of origin.
\end{abstract}

Keywords: circular migration, codevelopment, social remittances, local differentiation.

\footnotetext{
Doctora en Antropología Social, Universitat de Barcelona. Docente de la Universitat Oberta de Catalunya. Sus más recientes publicaciones incluyen: "Prácticas cooperativas: ¿estrategias de supervivencia, movimientos alternativos o reincrustación capitalista?” (2014), en Ars \& Humanitas: 151-164, y "¿Lazos de ayuda o patronazgo? La sostenibilidad de las nuevas economías agrícolas en la globalización: una comparación entre Catalunya y Siria” (2012), en Economías solidarias, economías sostenibles y economías cotidianas. nuriamorello@gmail.com.
} 


\section{Introducción}

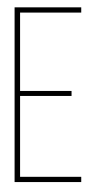

l caso etnográfico que expone este artículo forma parte de una investigación doctoral realizada entre Catalunya y Colombia durante los años 2011 y 2014¹. En esta se analiza un programa de contratación de mano de obra inmigrante para la recolección agrícola, el almacenamiento y el procesamiento de fruta dulce, promovido por un sindicato de pequeños y medianos agricultores, la Unió de Pagesos. Dicha propuesta de reclutamiento se caracteriza por la contratación de temporada y la aplicación de un programa de capacitación y orientación en la inversión de la remesa, con los países de donde provienen las personas trabajadoras. Se trata de un programa que se corresponde con un tipo de intervención enfocada en la promoción de medidas de retorno de la mano de obra inmigrante y que busca estimular y favorecer la gestión de las remesas (Ruhs 2006). Este tipo de experiencias se han teorizado como modelo migración laboral temporaly circular (MLTC) (Zapata-Barrero, Faúndez y Montijano 2009), y la experiencia particular que analizo ha sido estudiada por las ciencias sociales con el objetivo de dar luces sobre sus ventajas e inconvenientes (Kraft y Larrard 2007; Mejía et al. 2009; Roll y Biderbost 2009).

Examino el programa migratorio como una intervención sobre poblaciones centrada en una experiencia concreta de selección, contratación y aplicación de codesarrollo en los municipios rurales que han suministrado mano de obra desde Colombia, entre los años 1999 y el 2014, hacia la comunidad autónoma de Catalunya (Estado español). La aproximación a esta experiencia se realiza bajo la lupa de los análisis de escala y se ubica en los niveles intermedios de análisis de los fenómenos migratorios, para explorar los intereses individuales y colectivos que operan en la movilización de mano de obra internacional hacia los sistemas europeos de producción agroalimentaria. El examen de este sistema de aprovisionamiento laboral conecta dos localidades diferentes a escala transnacional y debe ser situado en una relación de transnacionalidad: la del campo catalán y sus explotaciones agrarias familiares industrializadas, y los grupos domésticos

Este artículo presenta algunos resultados del proyecto de tesis doctoral "Entre la oportunidad y el deseo. Contratación en origen, codesarrollo y grupos domésticos transnacionales en el mundo rural. El caso Catalunya-Colombia". El proyecto fue financiado por el Ministerio de Educación, Cultura y Deporte del Gobierno español, mediante la beca predoctoral Formación de Profesorado Universitario (FPU), entre el 2010 y el 2014. La tesis fue aprobada en enero del 2016 en la Universidad de Barcelona. El contenido del artículo proviene de un documento de trabajo presentado en la 5. ${ }^{a}$ Escuela de Verano "Movilidad social y desigualdades interdependientes: una nueva agenda para la investigación de las desigualdades sociales", realizada del 16 al 20 de marzo del 2015 en el Instituto de Investigaciones Sociales (IIS) de la Universidad Nacional Autónoma de México (UNAM), Ciudad de México. 
colombianos movilizados temporalmente para ser integrados como mano de obra asalariada en este sector económico.

En la exploración del ámbito intermedio y el engranaje de actores sociales involucrados en la migración, utilizo la sociedad de origen y de destino como un campo continuo de análisis, tal como fue planteado teóricamente por algunos debates de finales del siglo XX sobre los asuntos migratorios con perspectiva transnacional (Glick-Schiller y Çaglar 2008; Levitt 2001; Nyberg-Sorensen 2002, 2004; Vertovec y Cohen 1999). A partir de un enfoque que pretende estudiar los procesos transnacionales desde abajo, la investigación se centra en las prácticas de los inmigrantes y sus redes, así como en las instituciones involucradas en los procesos migratorios. Es decir, se enfoca en los agentes intermediarios extraterritoriales - organismo reclutador y ONG_, agentes locales como las alcaldías y las organizaciones campesinas participantes en los procesos de contratación y codesarrollo, así como en los proyectos de vida de los grupos domésticos inmigrantes y el papel de las personas “inmóviles”, en dos zonas de contratación del suroccidente colombiano (Valle del Cauca-norte del Cauca y Nariño).

\section{Metodología y trabajo de campo etnográfico}

Los antecedentes del trabajo etnográfico se remontan a un proyecto de investigación anterior sobre las relaciones capital-trabajo en el campo catalán y su mercado de trabajo segmentado étnicamente, que contó con dos fases de estudio (2003-2004 y 2009-2010)². Durante estas dos fases se documentó un proceso de sustitución de la mano de obra inmigrante africana y magrebí, que se justificó mediante discursos culturalistas, y que culminó con la implementación del sistema de contratación en origen como nueva estrategia de suministro de mano de obra inmigrante controlada por el Estado, procedente de Colombia y países de Europa del Este. Al explorar cómo se construyen categorías diferenciadas de trabajadores con base en la situación jurídica, la etnia, la raza y el género, las preguntas que motivaron la investigación actual se concentran en la influencia que ejercen los reclutadores en el lugar de origen y en el espacio de la intermediación en la configuración de los mercados de trabajo y la construcción de categorías 
de trabajadores y trabajadoras. ¿Qué perfiles se seleccionan? ¿Cómo entran a las comunidades y cómo implementan los proyectos de codesarrollo? ¿Son estas intervenciones neutras en términos de género? A partir de estos interrogantes, la investigación indaga por las relaciones que se establecen con las instituciones que promueven la migración y si se puede hablar de nuevas formas de jerarquización social y de colonialismo.

Por otra parte, también se interroga por los efectos locales que genera este sistema de contratación y la implementación de las iniciativas de codesarrollo. ¿Se producen nuevas transformaciones sociales o se modifican fenómenos existentes? ¿Se genera más desigualdad por la llegada de ingresos a los grupos domésticos con personas que trabajan en los campos y cooperativas catalanas? ¿Qué sucede en las redes de parentesco y las redes locales?

He trabajado con dos hipótesis: la primera plantea que la implementación del modelo MLTC no se produce con los parámetros de legalidad, control de flujos migratorios y estabilidad laboral que caracterizan el discurso del programa. Por el contrario, en sus prácticas cotidianas funciona en términos de empresa de la migración con ciertas actividades que rozan la informalidad. La segunda hipótesis explora los usos y significaciones de la remesa y plantea que la redistribución de los recursos de la migración va más allá de la capitalización empresarial de las remesas en manos de individuos en concreto. En esta redistribución operan lógicas clientelares locales entre redes extensas de ayuda mutua, que inciden en un proceso de diferenciación social y búsqueda de estatus, por encima de procesos de acumulación y desigualdad entre grupos domésticos migrantes.

Para realizar el proceso de contrastación llevé a cabo una inmersión etnográfica en el suroccidente colombiano que tuvo dos fases. La primera fue entre abril y octubre del 2012; en esta hice una primera prospección en varias experiencias de contratación y proyectos de codesarrollo aplicados por personas contratadas en origen. En la segunda fase tomé la decisión metodológica de comparar dos experiencias locales de contratación como estudios de caso. Por tal razón, hice una estancia de cinco meses (varias visitas entre noviembre del 2012 y marzo del 2013) en el norte del Cauca y otra en Nariño/Putumayo de dos meses y medio (de abril a junio del 2013), durante las cuales utilicé técnicas cualitativas de recolección de datos. Finalmente, en el 2014 hice algunas entrevistas puntuales en las cooperativas y los lugares de trabajo en Catalunya con personas contactadas en la fase de inmersión en Colombia ${ }^{3}$. Cabe señalar que la investigación tiene una

Durante el trabajo de campo etnográfico realicé observación participante al convivir en los hogares de los inmigrantes y estudiar de cerca los distintos momentos de la migración circular (llamada, para la siguiente campaña, partida hacia Europa, la vida sin la persona temporera 
dimensión temporal en la década del 2000, periodo de crecimiento económico y demanda de mano de obra en el Estado español, y en el 2014, momento en que los programas de contratación de temporada eran cuasi anecdóticos. Desde el 2008, el sistema que analizo empezó a disminuir drásticamente en el número de contrataciones, debido a la negativa del Estado español a conceder más cupos, ante el incremento del desempleo en el país y la crisis financiera.

Estudiar los efectos de la política de contratación en origen en los pueblos colombianos, cuando se empezaba a abandonar este tipo de programas, permite analizar el efecto de una política de movilidad de la mano de obra bajo una perspectiva temporal. Por lo tanto, me enfoqué en el rol de las personas inmigrantes en sus países de origen, así como en el de las personas que no emigran, las que se quedan, y los usos y significados que adquieren las remesas conseguidas en el exterior. Este hecho conlleva estudiar procesos a largo plazo. Además, exploré las asimetrías en los procesos transnacionales, en aspectos como la formación de empresas de la migración con diversidad de agentes e intereses involucrados e interconectados a escala transnacional, así como en los procesos de ascenso social y diferenciación local que se viven en el seno de estas conexiones transnacionales.

En este artículo expondré algunos resultados del estudio. Primero, describiré el modelo MLTC y su implementación en la agricultura española. En segundo lugar, analizaré una experiencia de institucionalización de la migración (Goss y Lindquist 1995) con intereses lucrativos. Finalmente, expondré de forma breve el caso de Obando en los Andes colombianos (Nariño) y cuatro situaciones concretas de los grupos domésticos protagonistas de esta experiencia. Así, se pretende discutir la relación entre la distribución clientelar de los recursos de la migración, la diferenciación social y la remesa social, en el seno de un proceso de reparto desigual de los beneficios de esta experiencia migratoria ${ }^{4}$.

y su retorno). También participé en las actividades de las organizaciones locales a las que pertenecían. Además, observé la actividad del organismo reclutador, su fundación y sus ONG colaboradoras; por ejemplo, acompañé a los técnicos en las visitas e intervenciones. Debo destacar que no tuve la oportunidad de observar procesos de selección, puesto que durante la estancia entre el 2012 y el 2013 tan solo contrataron a 500 personas y se habían cerrado los cupos concedidos por el Estado español. En total recolecté 6 genealogías familiares y trayectorias laborales de los miembros del grupo doméstico; 35 entrevistas a agentes sociales, poder local, asociaciones campesinas, ONG y temporeros, y documenté 11 proyectos productivos de codesarrollo.

4 Para mantener el anonimato uso nombres ficticios de las personas, los municipios, las organizaciones y las ONG analizadas. Los únicos nombres reales que se mantienen son el de Unió de Pagesos y Fundació Pagesos Solidaris. 


\section{Control de la movilidad geográfica y disciplina laboral}

La adopción del modelo MLTC se debe situar en el ámbito sociopolítico, en la generalización de políticas migratorias restrictivas, de cierre de fronteras y de persecución de la inmigración indocumentada en la Unión Europea y el Estado español. A partir del año 2000, en el Estado español se produjo un giro en el control de los movimientos de personas y su ingreso al mercado laboral: se aplicaron los convenios bilaterales de intercambio de mano de obra entre Estados, mediante los cuales se reguló una política de contratación en origen entre Estados colaboradores (Geronimi, Cachón y Teixidó 2007). De este modo, se priorizó la contratación circular y de temporada de trabajadores inmigrantes reclutados en origen y con permisos especiales de permanencia, que obligan a la persona a retornar una vez terminado el contrato, para ser reclutada nuevamente en la siguiente temporada. Es decir, la contratación de personas con una movilidad geográfica y laboral controlada. Este tipo de programas estatales de control y suministro de mano de obra no son nuevos en la historia. Desde la economía política se acuñó el concepto de sistema de trabajo migratorio (Burawoy 1976) para referirse a experiencias como el Programa Bracero entre México y Estados Unidos, el Gastarbeiter alemán o los programas de trabajador invitado — Guest Worker - de los países europeos en las décadas de los sesenta y setenta del siglo $\mathrm{XX}$. Este tipo de sistemas se caracterizan por una separación geográfica de las personas trabajadoras entre las esferas productivas (ámbito laboral en el lugar de destino) y las reproductivas (ámbito de la economía doméstica y del cuidado en el lugar de origen), por la regulación de la movilidad a través de agencias oficiales, y por la limitación de los permisos de residencia, la restricción de la movilidad laboral y la negación de los derechos políticos y civiles a la población inmigrante (Narotzky 2004, 123). En efecto, el inicio de la contratación en origen en la agricultura intensiva catalana supuso un cambio en las relaciones laborales, ya que se priorizó una nueva categoría de persona trabajadora, desprovista de derechos y disponible temporalmente. Este hecho implica una desigualdad jurídica y laboral en el marco de la inserción social de estas personas, que se acompaña de discursos culturalistas sobre la mano de obra.

En la investigación preliminar citada (2003-2004 y 2009-2010) se pudo contrastar el desplazamiento de distintas oleadas de trabajadores inmigrantes que eran empleados como mano de obra barata y sin documentación, para mantener las explotaciones agrarias ante los embates de su inclusión en un mercado 
europeo con exigencias de calidad y de suministro permanente de alimentos. Ante el reacomodamiento del sector mediante la tecnificación y la inversión, se produjo un crecimiento del endeudamiento de las explotaciones familiares a la vez que crecía la demanda de productos frescos. Durante los años ochenta se pasó de una mano de obra familiar, con contratación de estudiantes, cuadrillas de jornaleros del sur del país o de familias de etnia gitana bajo formas de patronazgo a la asalarización de las relaciones productivas. Al crecer la demanda de mano de obra, esta se nutrió de oleadas de trabajadores provenientes de África negra y del Magreb. Como indicó Berlán (1987), el control del factor trabajo fue la única opción de los agricultores para mantener sus explotaciones viables en el mercado. Por este motivo, desde los años noventa la estrategia de los agricultores consistió en combinar mano de obra en situación de legalidad jurídica con mano de obra en condición de irregularidad. Este hecho permitió abaratar el precio del trabajo (Jabardo 1999) pero ocasionó graves episodios de conflictividad social en el campo (huelgas y reivindicaciones de los sin papeles). Sin embargo, ante la gran persistencia de personas indocumentadas que el Estado se negaba a regularizar, se cambió la estrategia de suministro de mano de obra para hacerla más eficiente y controlada por el Estado y se instauró el sistema de la contratación en origen.

Las nuevas personas, contratadas en los países con los que se firmó un convenio bilateral, se insertaron en un mercado de trabajo caracterizado por la segmentación étnica y de género de la mano de obra y por unas preferencias empresariales hacia determinados colectivos, en términos de aptitud para el trabajo y en función de la cercanía cultural. Ejemplo de ello es la publicidad de la primera experiencia piloto del programa de contratación en origen en Lleida (Catalunya): "La adaptación es un factor clave, por lo que el idioma y el tener una cultura similar, así como la ausencia de conflictividad garantiza la continuidad de la experiencia”5 (Morelló y Sarkis 2013, 277).

Varios estudios sobre migraciones y mercado de trabajo en el sector agrícola español indican que, durante la primera década del siglo XXI, las personas provenientes de Latinoamérica y Europa del Este - muchas de ellas mujeresfueron los colectivos preferidos debido a ciertos atributos culturales que se les adjudicaban. Estos incluían la lengua, la confesión religiosa judeocristiana o la pertenencia a países europeos, además de ciertos atributos de género, por ejemplo la visión de las mujeres como más delicadas, disciplinadas y sumisas. Las siguientes citas de un informe sobre la contratación de trabajadores extranjeros 
en la agricultura (Unió de Pagesos 1999) nos indican cómo se construyen categorías de trabajadores por parte de organismos sociales intermediarios:

El país elegido es Colombia, debido a las afinidades culturales que nos unen con los países sudamericanos, como son la lengua, costumbres y religión, elementos fundamentales y facilitadores de la integración, tanto en el trabajo como en la sociedad. Fueron también motivos humanitarios los que impulsaron a elegir Colombia, la difícil situación que atraviesan diversas zonas afectadas por desastres naturales y por la confrontación civil que está sufriendo el país. (Unió de Pagesos 1999, 2) Sobre su posterior trabajo en el campo, destacar su buena adaptación y predisposición. Tal y como muestran los cuestionarios de evaluación laboral, la gran mayoría de agricultores destacaron su rápida capacidad de aprendizaje, carácter afable y ganas de integración [...].

A nivel general de adaptación a las costumbres del pueblo y a los agricultores fue rápida y positiva. No tuvieron ningún problema en aceptar y respetar la normativa interna que rige todos los alojamientos gestionados por la COAG-UP [...] Otra de sus costumbres era asistir periódicamente a la iglesia. La buena relación con el párroco del pueblo les llevó a visitarle en más de una ocasión a su casa particular, donde charlaban con él y les invitaba a un refrigerio. (Unió de Pagesos 1999, 6-7)

Por el contrario, otras experiencias con trabajadores provenientes de África y recluidos en el Centro de Estancia Temporal para Inmigrantes (CETI) de Melilla, con quienes también se hizo una prueba piloto, muestran un rechazo debido a una supuesta conflictividad:

En el momento de distribuir los trabajadores, 12 personas, la mayoría nigerianos, nos exigieron los permisos de trabajo y no entendían por qué habían de empezar a trabajar sin tenerlos. En vano fueron nuestras explicaciones, ya que les repetimos una y otra vez que los permisos se tramitarían una vez estuvieran trabajando, se mostraron violentos y dificultaron muchísimo la distribución de los trabajadores que se alargó hasta pasadas las doce de la noche. (Unió de Pagesos 1999, 3)

Esta construcción social de categorías de personas trabajadoras acompañó el desplazamiento de los colectivos de africanos y magrebíes en varios puntos de la geografía española y devino un tema ampliamente estudiado en el Estado español (Gordo 2008; Martínez 2001; Pedreño 2001, 2007; Reigada 2009). La particularidad del nuevo modelo recayó en que su implementación en Catalunya la realizó un sindicato agrícola (la Unió de Pagesos) que gestionó la contratación en origen de más de 7.000 personas desde el año 1999 hasta el 2014. En el 2006, uno 
de los años álgidos en este sistema, 1.240 de estas personas eran colombianas (Kraft y Larrard 2007, 3) ${ }^{6}$.

Además, el sindicato fusionó el reclutamiento, la selección e inserción de la mano de obra con un programa de intervención social o responsabilidad social empresarial: la implementación de proyectos de codesarrollo con las comunidades y pueblos de origen para "reparar los daños” y los efectos negativos que supone el trasvase de mano de obra inmigrante - pérdida de población activa en origen, explotación laboral, prohibición de derechos y discriminación en destino-, mediante capacitaciones y entrega de recursos para orientar la inversión de la remesa de los trabajadores. El discurso que englobaba estas intervenciones toma su referencia de la propuesta del eurodiputado Sami Naïr, al definir el codesarrollo con base en la consideración de que con la migración se debe conseguir un beneficio mutuo: que los países de envío no pierdan capacidades y capital humano y que se gestionen programas para frenar la pobreza y las causas de la migración (Naïr 1997). De este modo, los migrantes serían formados como agentes de codesarrollo para promover iniciativas en sus comunidades de origen, bajo la rúbrica del "emprendedor económico" o la “emprendimiento social”. En el caso estudiado, dicho principio se traduce en la implementación de programas diseñados para favorecer el retorno, mediante medidas que lo estimulen, como la gestión de impactos de las remesas (Kraft y Larrard 2007).

\section{Mercantilización de la migración y la solidaridad}

Como consecuencia del trabajo de campo en Colombia pude observar que, más allá de un programa de contratación e intervención sobre poblaciones desfavorecidas, este tipo de contratación no difiere mucho de las industrias migratorias que surgen alrededor de los movimientos migratorios a escala mundial. Estas constituyen un conglomerado heterogéneo de agentes sociales interrelacionados entre sí a través de las fronteras, y que se lucran con el movimiento de personas

Según los datos proporcionados por el sindicato, de la experiencia piloto con 34 personas colombianas en 1999 se pasó a la contratación de 1.389 en el 2002. En el 2007, 6.710 fueron contratadas en origen en el sector agrario de Lleida, de las cuales 3.837 fueron contratadas por la UP. El 28\% eran colombianas y el 72\%, de Europa del Este (Morelló 2010). Según un estudio de Kraft y Larrard (2007), desde Colombia fueron movilizadas 1.240 personas en el 2006. 
ya sea de un modo legal o ilegal (Hernández 2012). Para entender el conjunto de agentes vinculados en este estudio de caso, debemos tener en cuenta que se trata de un programa promovido por el Estado español, que transfiere a un organismo semiprivado - un sindicato de agricultores - las funciones de reclutamiento, entrenamiento, transporte y alojamiento de la mano de obra mediante canales legales (Achón 2011). Este, a su vez, proporciona el servicio a sus socios y clientes: las empresas agrícolas. Es decir, realiza las funciones de intermediación. Por este motivo, analizo el programa como una institucionalización de la migración, en términos de Goss y Lindquist (1995). Según estos autores, paralelamente a la proliferación de las redes migratorias como canales impulsores y facilitadores de la migración, existen instituciones para inmigrantes que las complementan: las instituciones migratorias. Estas se definen por ser una articulación compleja de individuos, asociaciones y organizaciones con intereses particulares, los cuales ejercen papeles específicos dentro de un entorno institucional (manejo de reglas y regulaciones) para acceder a los recursos. Además, extienden las relaciones sociales y la interacción entre agentes y agencias a través del tiempo y el espacio, para promover el acceso al trabajo internacional. La experiencia de intermediación estudiada se configura por la confluencia de varios agentes para gestionar el proceso y ofrecer servicios en forma de cadena de intermediarios. A fin de describir el programa, debemos detenernos en el fenómeno del reclutamiento y los procesos de selección, ya que los perfiles de las personas seleccionadas y las zonas de contratación son unos de los que caracterizan la particularidad de la intervención.

El programa se inició en el año 2000 con una primera contratación en zonas andinas del centro de Colombia (Cundinamarca) de donde provenían las personas reclutadoras, que eran a la vez socias del sindicato y estaban radicadas en el país latinoamericano. Posteriormente, el programa iría creciendo e institucionalizándose y formaría parte de las áreas prioritarias de intervención de las agencias españolas de cooperación internacional (2007-2013), como las zonas de conflicto armado. La figura 1 nos muestra la evolución de la contratación en Colombia del año 1999 al 2006.

Sin embargo, según datos proporcionados por la Unió de Pagesos, los años 2007 y 2008 fueron los de mayor contratación (1.401 y 1.257 personas, respectivamente). Por el contrario, a partir del 2009, la contratación descendió a 911. Como ya se indicó, durante mi estancia etnográfica este programa estaba contratando menos de $500^{7}$. 
Figura 1. Evolución del número de trabajadores temporales colombianos, 1999-2006

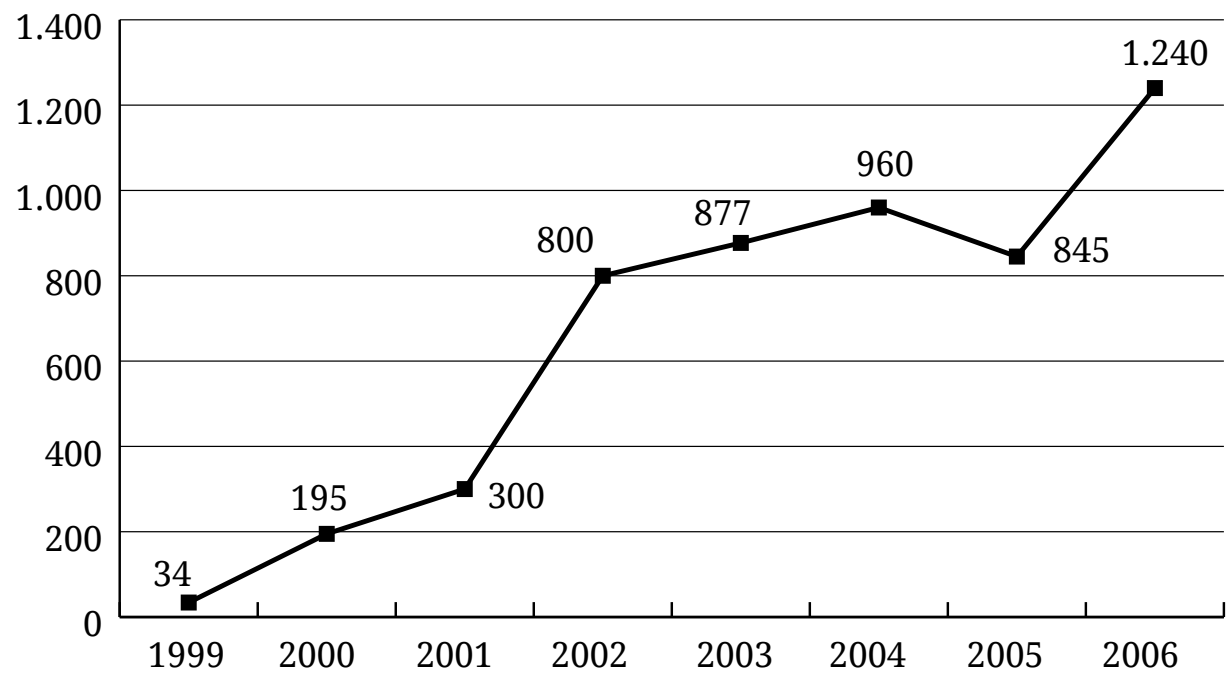

Fuente: Unió de Pagesos y Embajada Colombiana en Madrid (Kraft y Larrard 2007, 11).

La Unió de Pagesos entró a las comunidades por medio de las personas reclutadoras y a través de las asociaciones y organizaciones locales campesinas. El perfil idóneo que buscaban era el de personas familiarizadas con las tareas del campo que pertenecieran a organizaciones y asociaciones campesinas. Otro requisito para ser beneficiario del programa era que tuvieran un perfil socioeconómico bajo ${ }^{8}$. Asimismo, fomentaron la contratación de individuos con perfil de líderes, con cierta implicación social o con responsabilidades en sus lugares de origen a fin de garantizar el retorno al terminar el contrato. Las siguientes citas nos permiten entrever cómo se construyen categorías de trabajadores y trabajadoras desde la intermediación, y cómo esta influye en el lugar de destino al reforzar los procesos previos de segmentación de la mano de obra:

Había un perfil. Y este era que se tenía que tener un proyecto. Si uno iba, y después al regresar se gastaba toda la plata en alcohol, en una rumba en el pueblo, y ese era el primero que provocaba peleas, pues ya no se

8 Un estudio sobre el programa realizado en el 2007 pone de manifiesto que la mayoría de las personas contratadas eran población rural, joven y de origen social muy modesto. Sus sueldos medios antes del primer viaje hacia España oscilaban entre 32 y 80 euros por mes, según el pueblo de origen. En comparación, el sueldo medio colombiano en el 2006 era de 131 euros (Kraft y Larrard 2007). 
le volvía a llamar. Se priorizó a gente con familias, porque así tenían más responsabilidades. [...] Y me decían: "Es que es control social”. Y yo les dije: "Sí. Lo es. Pero este es el requisito para participar. Si no, que viajen con otro. Que paguen con intermediario”. Eso era un programa para que la migración revirtiera. (Amanda, reclutadora y gestora de la ONG intermediaria Colombia Solidaria, diario de campo, Nariño, 2013)

Por otro lado, se favoreció a las mujeres cabeza de hogar, con responsabilidades en origen y sin comportamientos sexuales considerados indebidos por parte de las personas reclutadoras. Dicho perfil daba mayor garantía de retorno, ya que, según una de las reclutadoras entrevistadas, las chicas jóvenes se quedaban en destino, al establecer relaciones sentimentales allí. De la siguiente entrevista podemos vislumbrar cómo desde las instituciones y las organizaciones intermediarias se fomentan comportamientos y perfiles deseables de la población a movilizar y se juzga el comportamiento sexual de las mujeres:

Ya en zonas donde llevamos mujeres solteras, pues igualmente vimos que muchas allí pues o con el patrón o con los hijos del patrón o con otros españoles se ennoviaban, y ya no regresaban. Y había unas historias de amor muy fuertes: que si el empresario que se enamoró, que si otra con el encargado... y luego volvían y tenían novio aquí. Pero muchas aprovecharon [...] Entonces empezamos también a llevar mejor mujeres que fueran cabeza de hogar, que ya tuvieran una responsabilidad y que tenían más necesidad que otras, que tuvieran como otra visión y en especial pues que no fueran tan bonitas, pues tan atractivas, para que luego allí pues no tuviera ese problema. En una selección que se hizo en Pereira, al final las escogí que no fueran bonitas. (Amanda, reclutadora y gestora de la ONG intermediaria Colombia Solidaria, Bogotá, 2013)

Otra particularidad de la contratación es que se creó una cadena de intermediarios para gestionar el proceso y ofrecer servicios. Primero fue la figura de los “operadores”, que se encargaban de los procesos de selección, contratos y suministro a la Unió de Pagesos en Catalunya, bajo la forma de empresa particular subcontratada. Es decir, a los empresarios catalanes se les cobraba por selección, entrenamiento, acompañamiento al aeropuerto, gestión de los contratos, transporte aéreo y seguimiento de la bolsa de trabajadores en reserva para la siguiente temporada en Colombia. Una vez llegados a España, una organización del mismo sindicato, la Fundació Pagesos Solidaris (FPS), se encargaba de la recogida en el aeropuerto, del desplazamiento hasta el lugar de trabajo, la acogida y alojamiento en albergues, la formación complementaria como agente de codesarrollo y el acompañamiento hacia el aeropuerto para el retorno. 
En un segundo momento se creó una ONG (Colombia Solidaria más tarde cedería esta función a la Fundación Agricultores Solidarios [FAS]) encargada de las capacitaciones en la selección, el seguimiento de proyectos y la asesoría técnica a las ONG o asociaciones de productores beneficiarias, que fueron convocadas para realizar el reclutamiento entre sus miembros y recibieron las subvenciones para proyectos de codesarrollo en territorio colombiano. Desde esta misma ONG se proporcionaban servicios como las formaciones de emprendedores y los procesos de selección en los pueblos (figura 2). Todo ello se hacía mediante convenios de colaboración con las alcaldías, las organizaciones de productores, la ONG, la operadora de los contratos y la Unió de Pagesos.

Figura 2. Esquema del programa de contratación y codesarrollo

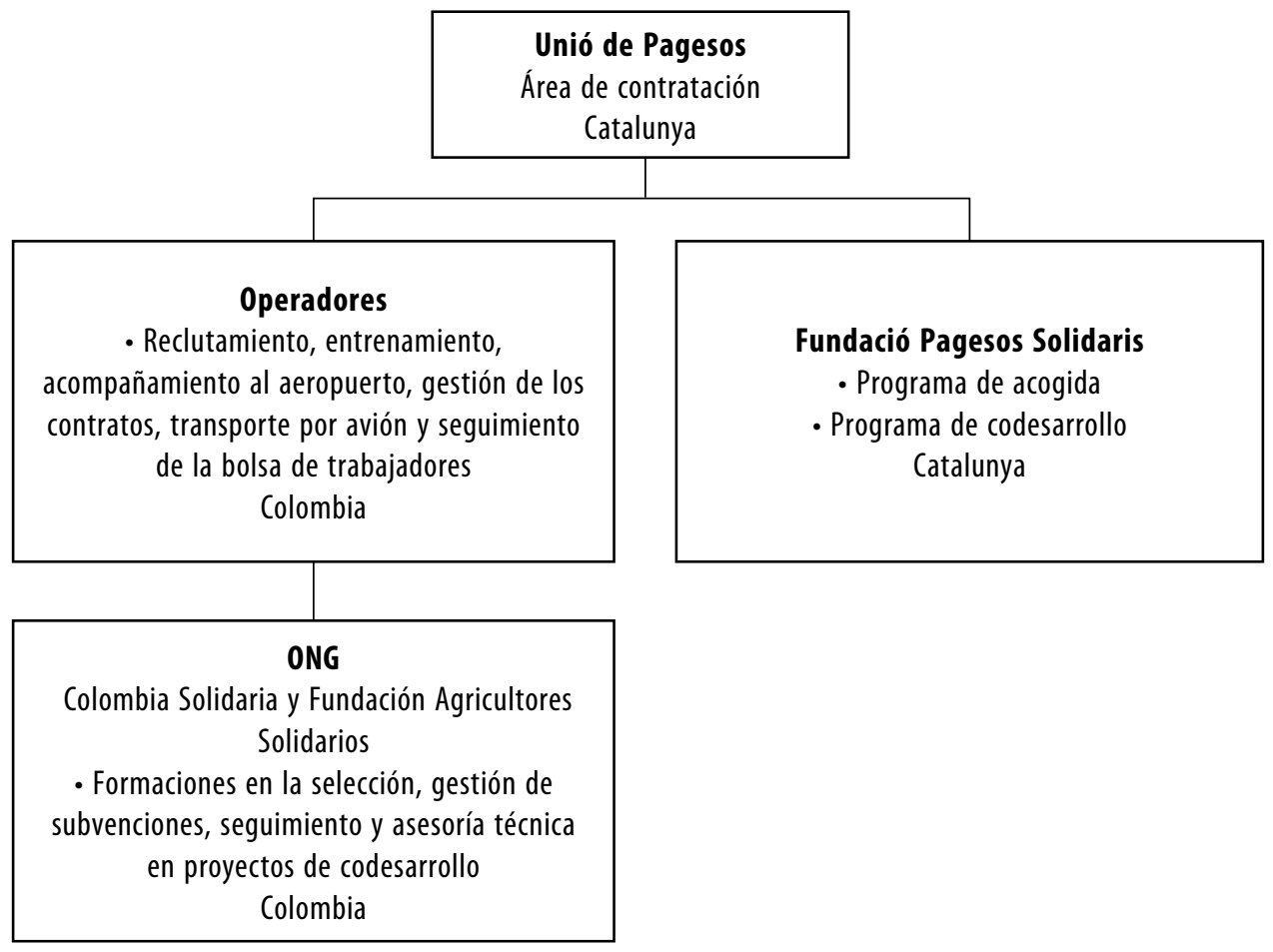

Fuente: elaboración propia.

En relación con la provisión de estos servicios, es pertinente hablar de empresas de la migración, puesto que el lucro obtenido del servicio al proceso migratorio es un hecho que se destaca en gran parte de las entrevistas. En este caso, por ejemplo, podemos encontrar señales de actividades mercantilizadas en las que la ONG Colombia Solidaria les cobraba a las alcaldías por el servicio del proceso 
de selección y por las capacitaciones brindadas; o el cobro de cuotas de mantenimiento a las personas seleccionadas (unos 20 euros al mes) por parte de las asociaciones campesinas. También se vendía a las alcaldías la oportunidad de ingreso a un proyecto de codesarrollo. Durante las entrevistas, algunos de los exempleados de la ONG y de la Fundación Agricultores Solidarios comentaron que, en la última época de convenios (del 2006 al 2010), en muchos municipios colombianos se firmaron convenios en los que las alcaldías tenían que reembolsar 500 euros por cada cupo personal a la Unió de Pagesos. Esto significa que la organización del proceso de selección en un municipio, con la escogencia final de 30 personas, sus posibilidades de formación como agentes de codesarrollo y la recepción de subvenciones para los proyectos formulados era una mercancía que se vendía a las alcaldías. Es decir, se cobraba por un servicio migratorio y por la entrada al programa de codesarrollo y sus posibilidades de generar proyectos productivos o sociales. En contrapartida, las alcaldías debían responder económicamente para dar la oportunidad a sus ciudadanas y ciudadanos: debían sufragar el acceso al programa. Sin embargo, en el 2010 se comprobaron irregularidades en los pagos, por ejemplo, el cobro adicional del servicio sobre las mismas personas reclutadas por los agentes locales. Desde dos zonas muy diferentes, con realidades locales distintas (Putumayo y Cesar), varias temporeras denunciaron el cobro anual de estos 500 euros por parte de élites locales, alcaldes o los mismos familiares para poder viajar. El siguiente caso da cuenta de la relación establecida entre el grupo gestor del programa de una comunidad cercana a Mocoa, en el sur de Colombia, y las personas a las cuales habría favorecido:

Entonces dizque le dijo: "No, pues si usted quiere regresar a España, me hace el favor”, dizque le dijo: "A esta cuenta”. Mi sobrino le dijo: “¿A cuál cuenta?”. “A esta cuenta, por favor”. Le decía: “iQuiere que le dé el número de cuenta para que consigne? Si no me consigna usted, ya sabe que de España le echo”. Y tres meses, y él no había dado ese ahorro. Entonces por eso fue amenazado. (Temporera, Colombia, junio del 2013)

En otros casos, por ejemplo en Valledupar (Cesar), otros entrevistados hablan directamente de la compra de votos por parte de las autoridades locales y del caso omiso que hizo uno de los reclutadores a este hecho:

El gobernador, a través de su gobernación y de los alcaldes del municipio donde había personal, aprovechaba políticamente: "Yo te mando a tu hijo, yo te mando a tu hermano para España, y tú me consigues votos”. El alcalde, en cada barrio, en cada vereda, en cada junta de acción comunal, ya habían hecho su selección. "Pues mira, consígueme cincuenta personas para viajar a España. Cada persona, que consiga cinco personas para votar, y estas cincuenta irán a España”. Pero antes, cada 
grupito, cada sección local, cada municipio, cada vereda, tenía su selección interna, y mandaban una o dos personas. [...] El papel de la Unió de Pagesos era: pues, si han seleccionado a doscientas personas, pues a mí me toca tanto, a usted, tanto y al otro, tanto. Pues él no tenía constancia de que esto pasaba, esto no les interesaba. Él sí que venía. Y estaba en parrandas con el gobernador y cosas de estas. De la selección y quién va y quién no va, pues no entraba. (Víctor Manuel, temporero, Lleida, Catalunya, España, octubre del 2014)

En consecuencia, el control ejercido sobre el funcionamiento del programa quedó fuertemente cuestionado y, desde Catalunya, se expulsó a varias personas que trabajaban en el programa, entre ellas un responsable de los reclutadores. Además, se demostró la opacidad y la arbitrariedad en los procesos de implementación del programa en varios puntos del territorio colombiano. La experiencia etnográfica descrita nos muestra cómo las prácticas de selección, el modo de entrada en las localidades rurales de los reclutadores y los agentes sociales involucrados en el proceso (alcaldías, asociaciones, organizaciones y líderes locales) interactúan en una estructura institucional que fomenta las migraciones. Se trata de una conexión de agentes sociales con agentes políticos institucionales. Por otro lado, como acabamos de observar, a pesar de estar reguladas formalmente por normativas estatales o internacionales, sus prácticas se fusionan con procesos políticos y económicos de tipo informal. Esta conclusión se reafirma con estudios previos sobre este programa, los cuales señalan casos de clientelismo en las comunidades en relación con los procesos de selección (Cabezas 2011, 57; Kraft y Larrard 2007, 60; Sánchez y Faúndez 2009, 9).

\section{Intermediarios y remesa social en la Colombia campesina: el caso de Obando (Nariño)}

La experiencia del pueblo andino de Obando y la Asociación Campesina Nacional de Obando (ACNO), con la que se hizo el reclutamiento, constituye un ejemplo etnográfico de la interrelación entre individuos, grupos de afinidad gremial, de parentesco y agentes sociales en el contexto del reclutamiento y la implementación del codesarrollo. 
Figura 3. Mapa político de Colombia con señalización de la zona sur de Nariño y del Putumayo, donde se desarrolló el trabajo de campo. El municipio de Obando se ubica entre Pasto y la frontera con Ecuador

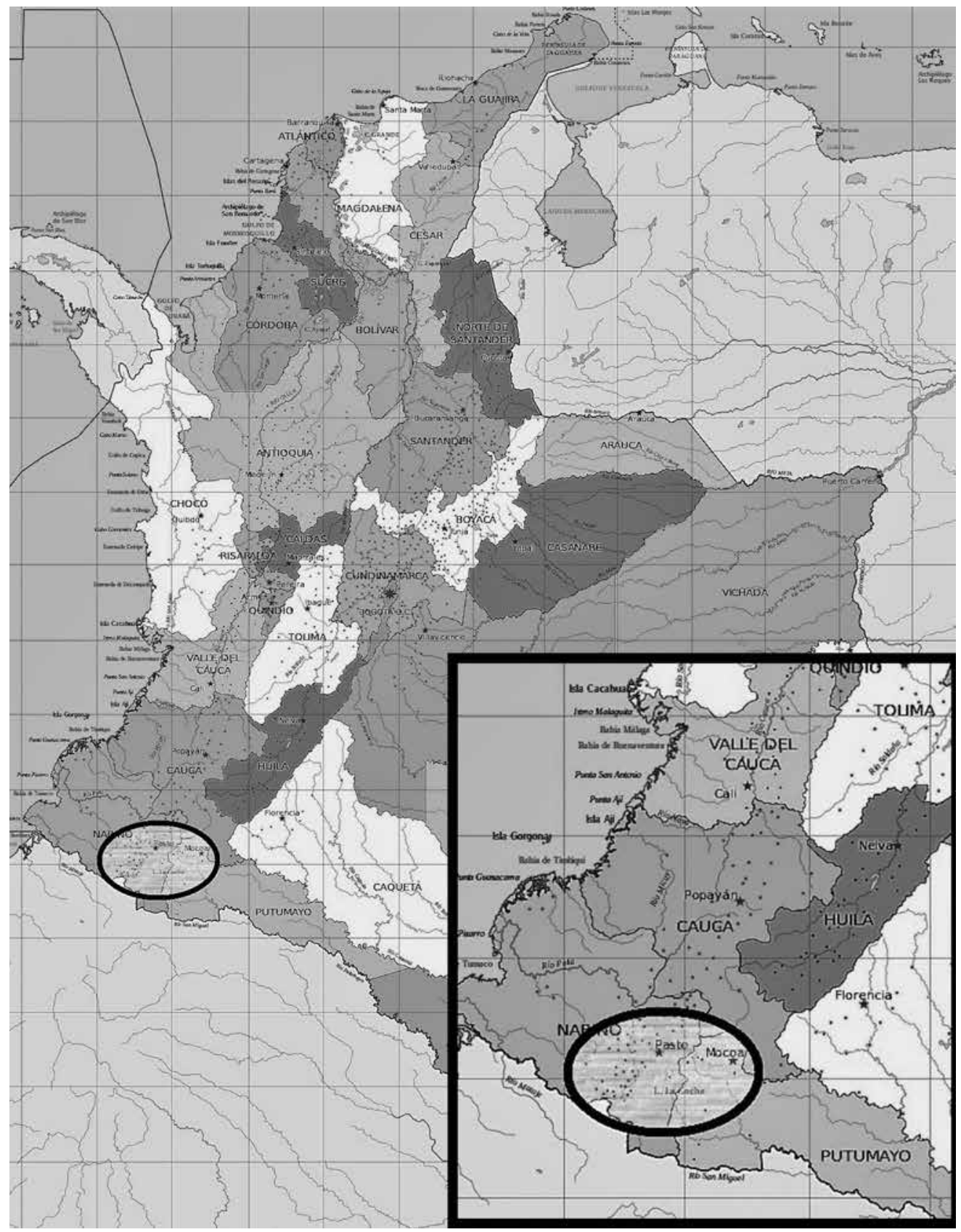

Fuente: https://commons.wikimedia.org/wiki/File:Colombia_Mapa_Oficial.svg. 
Obando es un municipio localizado al sur de Colombia, en una región campesina mestiza e indígena limítrofe con Ecuador (figura 3). Se ubica en la parte andina del municipio y tiene 8.500 habitantes, de los cuales 2.834 viven en el centro poblado. La estructura de la propiedad es minifundista, es decir, hay muchos propietarios con parcelas muy pequeñas y distintas formas de tenencia y arriendo de la tierra. Como otras zonas de Colombia estudiadas por las ciencias sociales - por ejemplo, Boyacá y el célebre estudio de Fals Borda, Campesinos de los Andes ([1955] 1978) — , la zona de los Andes de Nariño se caracteriza por la pobreza y el abandono estatal del campo. Durante el siglo XX vivió varios fenómenos de penetración capitalista, como la construcción del oleoducto transandino que conecta la región amazónica del Putumayo con la costa del Pacífico. También, como consecuencia de la pobreza campesina, fue escenario de un proceso de migración y colonización hacia tierras baldías de la parte amazónica del Putumayo, donde a partir de los años ochenta se produjo el auge de la economía de la cocaína.

Autores como Vargas (2003, 120-139) señalan que en la década de los noventa se vivió una crisis agrícola sin precedentes en toda la región, como consecuencia de la apertura neoliberal y sus exigencias de integración comercial. Al carecer de condiciones de competitividad, el PIB departamental y el índice de renta per cápita cayeron debido a la entrada de cultivos importados de Ecuador y Canadá. Las superficies cosechadas también cayeron en un 55\% en 1994, y las consecuencias para los agricultores fueron el empobrecimiento y la ruptura de sus tradiciones asociadas a los ritos de producción campesina. De este modo, se reactivaron procesos de migración interna hacia las zonas de producción cocalera y se introdujeron los cultivos ilícitos en la zona. En este contexto, en los años noventa, Obando y toda la región vieron cómo se generalizaba el cultivo de amapola, por lo cual se convirtieron en objeto de intervención estatal e internacional a finales de la década, con planes de desarrollo alternativo diseñados en Estados Unidos y paralelos al Plan Colombia (Vargas 2003, 139) ${ }^{9}$. En tal ambiente social y político y de aplicación de políticas de sustitución de cultivos ilícitos, el programa de contratación en origen y codesarrollo fue utilizado como un recurso por parte de esta nueva infraestructura de intervención. También fue una forma de acceso a recursos para las poblaciones intervenidas.

Don Javier, de origen campesino e indígena, y un grupo de seis socios más eran los líderes de la asociación principal del pueblo, la ACNO, y representaban a sus veredas (tres de los grupos domésticos estudiados en profundidad pertenecen

9 Para más información sobre las intervenciones en programas de desarrollo alternativo y programas de erradicación forzosa, el Plan Colombia y su relación con la evolución del conflicto armado en el suroccidente colombiano, véase Vargas (2003). 
a esta organización). En el año 2000, don Javier hizo un llamado a la Embajada española para solicitar recursos de cooperación para el desarrollo y hacer efectiva la sustitución de cultivos de uso ilícito. Es decir, la entrada de la Unió de Pagesos, la ONG Colombia Solidaria y la posibilidad de la migración internacional se produjeron en estas circunstancias de reclamo local de recursos externos. Así, en este pueblo de pequeños productores de papa, leche y amapola se dio un fenómeno local de boom con la introducción de la contratación, los procesos de selección y la entrada de recursos económicos para proyectos cooperativos. Durante diez años, más de doscientas personas de diez organizaciones de productores locales viajaron como trabajadoras hacia la agroindustria catalana.

De este modo, se hizo un proceso de selección basado en la formación de líderes (cursos de emprendimiento y turismo solidario), gestionado por la reclutadora - que era, a su vez, directora de la ONG Colombia Solidaria-, don Javier y la alcaldía como organismo financiador. Así nos describe un exempleado de la ONG los primeros contactos efectuados en estos municipios andinos y las maneras como se entró en las localidades:

Usted piense que cuando llegaba ella, eso todo era una fiesta, llegaba allá con la alfombra roja. La llevaban custodiada, en carro, con orquestra y todo. Se armaba un evento en el pueblo. Claro, estar bien con ella era importante, era la que llevaba todos los contratos. (Juan, extrabajador de la FAS y coordinador de proyectos, diario de campo, Bogotá, marzo del 2012)

Las primeras personas en viajar fueron los mismos líderes y socios (hombres y mujeres) de la ACNO y sus familiares. Después del éxito de la primera experiencia, más socios se presentaron en la selección y la posibilidad de migrar se instaló rápidamente en la mentalidad de la población. En los primeros años de la experiencia, el criterio de selección era la pertenencia a la ACNO y se daba prioridad a las personas que llevaban más años ejerciendo liderazgo y trabajo comunitario. Además, el proceso de selección se amplió hacia otras asociaciones de productores del pueblo, con el propósito de elegir a los líderes o a las personas más implicadas en la organización y su trabajo comunal.

Durante mi estancia etnográfica, las personas informantes (miembros de la asociación y gente del pueblo) mencionaban el constante conflicto social que hubo durante los más de diez años de emigración a España. Según ellas, todo el proceso siempre fue opaco y estuvo centralizado por la junta de la ACNO y las personas reclutadoras. Es decir, se produjo un fenómeno de acumulación y concentración de información entre don Javier, la ONG Colombia Solidaria y los reclutadores catalanes. Además, la experiencia se destaca por la activación de 
formas patrón-cliente en el seno de las asociaciones y en las veredas de donde provenían los socios. Este era un mecanismo social mediante el cual las personas con interés en ser reclutadas rendían fidelidad y proporcionaban trabajo a las organizaciones:

Que me han dicho que entre [a la ACNO], que al igual salen unos viajes a España. Él fue ganando puntos y puntos en la asociación, trabajando en las fiestas, de noche... y al final viajó. (Doña Nidia, socia de la ACNO y esposa de temporero, Obando, abril del 2013, diario de campo)

Éramos bastantes socios, o sea, de aquí las personas que se elegían era con base al trabajo, a su dedicación, a su tiempo invertido aquí, según eso, según su interés en la asociación se lo premiaba, que se podría decir... se le daba la oportunidad de salir. (Grupo focal socias ACNO, Obando, septiembre del 2012)

Alrededor de los socios principales se intensificó el intercambio de solidaridades, favores, apoyos políticos y, a veces, dinero ${ }^{10}$. A mayor afinidad o cercanía familiar, más posibilidades de viajar. Por ejemplo, si una persona quería participar en el programa tenía más garantías de ser seleccionada si era familiar de algún líder, miembro implicado de una asociación que le diera legitimidad para ser escogido o realizar un curso formativo de un año con todos los demás candidatos y candidatas. Por eso, un buen número de personas entrevistadas comentaba que “todo el mundo quería poner a los suyos”, y la experiencia se caracterizó por la conflictividad en torno a los cupos. Como consecuencia de la ambigüedad y poca objetividad de los criterios, muchas personas mencionan que la decisión final era de don Javier y los tres socios principales, y que los apoyos políticos y los pagos por viajar eran algo común. En consecuencia, se generaron sentimientos de injusticia en las personas no seleccionadas y se enrareció el ambiente en el pueblo, hasta el punto de llegar a peleas entre facciones locales de las veredas rurales, así como dentro de la misma organización entre partidarios y detractores de don Javier.

Lo destacable de la experiencia de Obando es que las organizaciones y los mismos gestores locales son claves en el proceso migratorio. La ACNO obtuvo

10 Es de señalar también que, durante la inmersión etnográfica, varias personas en diferentes localidades hacían alusión al intercambio de favores sexuales con los líderes de las asociaciones y algunos reclutadores. Dichas percepciones y rumores fueron difíciles de verificar puesto que se trataba de un tema extremadamente sensible. Sin embargo, dan cuenta de las percepciones locales en torno al programa y a las posiciones de desventaja de algunas mujeres para ser contratadas y aceptadas en el cupo local. También, de cómo el nivel de movilización de recursos e intercambio de favores trasciende hacia el ámbito del control del cuerpo de las mujeres. 
una fama sin precedentes por ser una asociación campesina que intermediaba en el proceso de reclutamiento y selección. Además, sus líderes campesinos fueron los primeros en viajar, formarse y conocer el proceso. Estos funcionaron como filtro para seleccionar y favorecer a las personas de su grupo de afinidad política y de parentesco, y tuvieron la capacidad de ampliar el programa hacia municipios vecinos. Con este precedente surgieron más asociaciones de productores en el pueblo y en otros municipios cercanos, pero la selección siempre estaba a cargo de la ONG y la operadora de contratos. Por su lado, don Javier, como contratista de Colombia Solidaria, se encargaba de buscar a las familias con el perfil sociodemográfico más bajo y animó la creación de nuevas asociaciones. Durante mi estadía en campo, muy pocas perduraron y algunas de las que quedaron activas formaban parte de una red de asociaciones beneficiarias de la ONG Colombia Solidaria, muchas de las cuales mandaron a sus miembros a España y recibieron intervenciones técnicas y financiamiento para proyectos productivos.

Por otro lado, se pudo observar el gran número de asociaciones de productores registradas en la Cámara de Comercio de la zona (44), muchas de ellas (25) creadas ad hoc a partir del 2001. En su momento, estas fueron utilizadas estratégicamente para la movilidad geográfica y social: mandar miembros del grupo doméstico a Catalunya a fin de obtener ingresos y mejorar la vida bajo el imaginario del sueño europeo. Otros estudios sobre el mismo programa nos indican un dato similar. Según Mejía et al. (2007), en algunos municipios de la misma región, la exigencia de ser parte de una asociación como requisito para ingresar al programa conllevó la creación de “organizaciones de papel, sin existencia real o con proyectos inviables y sin sostenibilidad, creadas apenas con el propósito de satisfacer la demanda de los reclutadores” (141-142). A pesar de ello, de acuerdo con el estudio citado, la presencia del programa en algunos municipios activó la vida comunitaria y económica.

En este punto, junto con el rol transnacional que desempeñan los agentes colectivos locales que no se desplazan y permanecen en el lugar, lo que se pretende vislumbrar es la presencia fundamental de los factores extraeconómicos en los procesos migratorios. Para analizar la experiencia de Obando, debemos recurrir a la antropología económica y su definición de la actividad y el comportamiento económico, en relación con procesos que van más allá del mercado, los mecanismos de oferta y demanda, la maximización del beneficio y el cálculo racional del homo economicus. La antropología económica toma como referencia instituciones, comportamientos, trabajos y relaciones sociales no mercantilizadas que aparecen ocultas en la economía neoclásica. Como bien lo indicó Polanyi ([1957] 1964), las actividades económicas se encuentran incrustadas en 
un conjunto de instituciones sociales y políticas así como de procesos informales, que incluyen factores morales, favores y obligaciones. Bajo el mismo prisma analítico, Wolf (1980) señala la importancia funcional de los grupos informales en el estudio de las instituciones formales. Según este autor, el sistema institucional de poderes económicos y políticos coexiste y se coordina con estructuras no institucionales, intersticiales, suplementarias o paralelas a este, y estas estructuras paralelas están en relación con instituciones de parentesco, amistad y patronazgo. Cabe señalar que las relaciones sociales locales asociadas a la migración que se viene describiendo se sitúan en la relación ambivalente entre interés, obligación y solidaridad, y en la relación de don y contradón descrita por Mauss ([19231924] 2002). En el caso de Obando, dichas instituciones son claves para entender el fenómeno del reclutamiento, la promoción de la migración y la redistribución de sus beneficios, a partir de la activación de lógicas clientelares en el seno de asociaciones voluntarias de individuos que se rigen por solidaridades gremiales campesinas; pero también en las solidaridades y favores que tienen lugar dentro de los grupos domésticos y las relaciones entre parientes. Entonces, el ejemplo etnográfico nos sitúa ante la dimensión y el significado político que deja la impronta de la migración a escala local, así como el uso del estatus y el prestigio derivados de la inducción a la migración. Todos estos efectos van más allá de una racionalidad individual calculadora de costos y beneficios en el hecho migratorio y son parte del análisis del significado que adquiere ganar, recibir, enviar y —en nuestro caso- administrar el dinero a través de las fronteras (Lacomba y Sanz 2013).

Por este motivo, el artículo propone analizar el caso de Obando y la ACNO en términos de la redistribución clientelar de los beneficios de la migración y de la remesa social. Por un lado, debido a la habilidad de los individuos y agentes sociales de manejar y distribuir los recursos de la migración, gracias al conocimiento adquirido de normas, reglas y contactos con personas claves a través del tiempo y del espacio. Por otro, al hablar de remesa social, debemos referirnos al ámbito de las transferencias de recursos tangibles e intangibles obtenidos por las personas inmigrantes en la sociedad de recepción, y con ello debemos entender la dimensión social y simbólica del dinero.

La primera investigadora que dio una definición de remesa social fue Peggy Levitt (1996), quien la entiende como ideas, prácticas, identidades y capital social que se remiten hacia el lugar de origen, permean la vida cotidiana de quienes quedan atrás y producen transformaciones sociales. Según su criterio, las hay de tres tipos: 1) la remesa social como estructura normativa, que se refiere a las ideas, valores y creencias, así como a las formas de comportamiento, responsabilidades familiares, relaciones de vecindad y comunitarias, y movilidad social; 
2) remesa social como sistema de prácticas y acciones que dan forma a la estructura normativa (formas de participación o delegación de tareas), y 3) remesa social como capital social. Aquí la autora considera los valores y las normas que rigen el capital social por sí mismo como remesa social. Por otro lado, autores como Goldrin (2002), Nyberg-Sorensen (2004) o Kearney (1996) señalan que no solo circulan y se envían elementos monetarios - dinero y divisas-, productos y tecnologías que adquieren las personas migrantes o los negocios productivos que puedan emprender. Cuando estos autores hablan de remesa social se refieren a los aprendizajes adquiridos en el extranjero, al significado que tiene cambiar los consumos, a cómo los inmigrantes se hacen presentes en la comunidad, a cómo se reconfiguran identidades o al aumento de estatus social a partir de la transferencia de recursos de un país a otro ${ }^{11}$. Algunos de estos aspectos se conjugan en el caso expuesto. Sin embargo, el uso del concepto de remesa social en este estudio se refiere a la relación social que se oculta tras el hecho de mandar, recibir y gestionar el dinero y los recursos entre receptores y emisores. Se entienden las remesas sociales como dinero obtenido por una o varias personas migrantes y que se utiliza en los ámbitos familiar y colectivo — subvenciones en codesarrollo, por ejemplo-, así como al capital social y los conocimientos adquiridos en las experiencias migratorias por parte de las personas inmigrantes. Asimismo, se utiliza el concepto transferencia para aquellos envíos de dinero y recursos asociados a los efectos y dinámicas económicas en el campo migratorio - por ejemplo, el recibo de subvenciones económicas y de la cooperación internacional por parte de la ACNO después de crecer como asociación o el pago a don Javier por trabajar como intermediador-.

Veámoslo más detalladamente. Primero, como consecuencia del conocimiento alcanzado durante las primeras experiencias migratorias, tanto don Javier como los socios de la ACNO desempeñaron un papel importante en la política local, en la gestión de recursos y cambiaron su estatus e influencia. Dicho de otro modo, acumularon capital social migratorio, gracias a su habilidad para

Según Lacomba y Sanz (2013), hay una dificultad en los estudios migratorios y en las ciencias sociales y económicas para encontrar un consenso y una precisión sobre el concepto de remesa. Señalan la pérdida de la capacidad heurística del concepto de remesa social, por la popularización y su uso extensivo y elástico. Así, la complejidad y la variedad en el tipo de transferencias los lleva a establecer una tipología con base en la sistematización de más de treinta tipos de remesas utilizadas en la literatura migratoria. En su tarea de trabajar la dimensión no estrictamente económica de la actividad de mandar dinero, proponen diferenciar remesa social de efectos sociales del envío y recibo de las remesas. Además, se inclinan por utilizar el término transferencias, que incluye no solo distintos tipos de capitales, sino diferentes clases de envíos e intercambios en el espacio social transnacional. Con el término transferencia se refieren al entramado de intercambios, vínculos y obligaciones, y proponen el término remesa como concepto de carácter técnico referido específicamente al envío de dinero (carácter monetario) (59-72). 
movilizar recursos externos y obtener más recursos sociales y políticos. Así lo relata don Javier:

Al principio yo iba como temporero y asumí la responsabilidad de representar a los temporeros allí, pues una vez allá mucha gente no se adaptaba. Hubo tres o cuatro casos de depresiones y yo me puse a atender a estas personas [...] pero vi que lo mío era el desarrollo comunitario y decidí quedarme [...].

Hice contactos allí con los encargados. Entonces, yo trabajaba con la esposa del payés ${ }^{12}$, con sus hijos, y empezamos a realizar una relación de tipo familiar. Nos daban la comida que ellos tenían y nos empezamos a contar cosas. Hicimos una relación más que de amistad, de tipo de trabajo cercano, donde ellos iniciaron a comentar sobre las luchas de Catalunya, donde ellos hicieron, incluso los más viejos..., que eran de mucha sensibilidad, el amor por la tierra, por el trabajo, el respeto... lo tienen... Yo les iniciaba a hablar la parte comunitaria. Y me decían: "Si ustedes son indios, ¿y por qué no conservaron la lengua como lo hicimos nosotros?” [...]

Entonces me postularon como agente de codesarrollo, porque hubo momentos en que no estaba trabajando y allí conocí a la fundación y a sus encargados. Yo era una de las personas que tenían en cuenta y yo le daba los méritos a Colombia Solidaria. A mí me tenían señalado de acuerdo a la estrategia como: "Aquí está un rumano, aquí los paisas, aquí los negros, y este que tiene el color de indio, pues ponerlo aquí”. Y yo tenía pues el cuento de la parte indígena. Era esa clasificación social y racial. Les convenía mostrarme a mí por mis facciones físicas como indígena. Yo sentía que me estaban utilizando. Pero yo también hice mis contactos. Con lo de la quinua, con lo de los productos. Exportar la quinua $^{13}$, el cuy ${ }^{14}$, proyectarlos como alimentos [...]

Y ese poder era, pues a raíz de que ya sale el primer grupo, pues con veinte personas, y pues después veinte más. Y con esa parte de viajar a Europa, que se puede decir que es algo que no se puede pagar alguien sencillo. Es algo que ni los gobernantes más grandes del departamento no van a tener la facilidad de desplazarse allí como teníamos nosotros. Pues éramos el punto blanco en el pueblo, y con un poder grande, que si hubiéramos querido, pues hubiéramos podido obtener la alcaldía.

12 El término payés es una traducción en español de la palabra catalana pagès, que significa campesino o agricultor.

13 La quinua es un cereal andino de origen precolombino, que se cultiva principalmente en Perú, Colombia y Ecuador. Después de siglos de abandono, desde el año 2000 hasta la actualidad ha sido objeto de políticas de recuperación en estos países. El programa descrito constituye un ejemplo de ello.

14 El cuy es un roedor de alto valor proteínico muy apreciado en la gastronomía de algunas zonas andinas de Perú, Bolivia, Ecuador y el sur de Colombia. Su consumo se remonta a la época precolonial. 
A mí me propusieron varios grupos, casi unánime, que intentara acceder a la alcaldía. Me ponían de alcalde. Pero yo no estaba interesado en la política. Aun así, me convertí en el ataque de los políticos. (Don Javier, exlíder de la ACNO, Obando, junio del 2013)

El hecho de que la ACNO centralizara funciones en la selección de trabajadores y la introducción en el mundo de los proyectos de cooperación internacional generó nuevos grupos de liderazgo, los cuales crearon sus propias redes de contactos e influencias y dieron el salto hacia la política local. El grupo central que gestionaba la junta de la ACNO utilizó el prestigio y el estatus social que obtuvieron tramitando y conociendo el proceso migratorio, siendo miembros inmigrantes y receptores de remesas. Además, durante los años más álgidos de la contratación, se recibieron fondos para implementar tres proyectos comunitarios de codesarrollo: una panadería de mujeres, uno de comercialización de quinua y otros de comercialización de alverja. Por otro lado, el resto de asociaciones participantes y sus miembros postulados como agentes de desarrollo entraron también en la fiebre de la formulación de proyectos de desarrollo aplicados a la economía campesina.

Gracias a la gestión del proceso migratorio y a la participación en proyectos de cooperación internacional en etnodesarrollo y desarrollo rural sostenible, la junta de la ACNO y don Javier a su mando aglutinaron recursos, contactos y redes clientelares que les permitieron organizar un cabildo indígena ${ }^{15}$ al margen de la alcaldía local, con una controvertida reformulación identitaria de lo indígena. Los intentos por constituir el cabildo generaron una gran oposición y deben ubicarse en el contexto de otros conflictos relacionados con el acceso al poder local. Parte de los socios de la ACNO, así como de otras asociaciones, se reivindicaron como campesinos y manifestaron un sentimiento de injusticia ante la gestión de la contratación en origen y los proyectos de codesarrollo por parte de la ACNO. Dichos sectores acusaban a sus líderes de ser falsos indígenas y al proyecto, de ser fraudulento, puesto que se sentían estafados por la gestión migratoria. Por su lado, algunas de las personas de la organización que apostaban por la reformulación

15 Según el Ministerio del Interior del Gobierno colombiano, un cabildo indígena es una entidad pública especial, cuyos integrantes son miembros de una comunidad indígena, elegidos y reconocidos por esta, con una organización sociopolítica tradicional, cuya función es representar legalmente a la comunidad, ejercer la autoridad y realizar las actividades que le atribuyen las leyes, sus usos, costumbres y el reglamento interno de cada comunidad. Por otro lado, cabe destacar que el reconocimiento por parte del Estado colombiano de las instituciones sociopolíticas propias de las comunidades étnicas se remonta tanto a las luchas del movimiento indígena colombiano, que consiguió la aplicación del Convenio 169 de la OIT en los años noventa, como a los movimientos afrodescendientes que negociaron la Ley de Comunidades Negras (Ley 70 de 1993). Mediante las nuevas legislaciones, se deben garantizar los derechos de propiedad colectiva y medioambiental de las comunidades étnicas colombianas. 
identitaria provenían de descendencia indígena del pueblo pasto, se reivindicaban como tal en un proceso de recuperación y querían conseguir recursos mediante instituciones propias. Durante la inmersión etnográfica existía una gran crispación local en torno a este tema que dificultó enormemente la tarea.

Por otra parte, durante el 2011, algunos de los líderes de la ACNO se presentaron a las elecciones municipales, lo que produjo una fuerte pelea local entre facciones afines al nuevo proyecto y facciones afines a la alcaldía. La reclutadora y directora de Colombia Solidaria describe así parte de la incidencia política local que se derivó de su promoción de la contratación y las formaciones en codesarrollo:

Dentro de la ACNO y las formaciones teníamos la parte de recuperación de la memoria, del pasado indígena y la identidad. Hubo un grupo que hizo este proceso de recuperar su identidad y reivindicar lo indígena, y entonces surgió la separación, porque el otro grupo no se sentía indígena. Ellos sí que de verdad hicieron un proceso válido. Don Javier era un $m a n^{16}$ muy piloso y se quedó trabajando en Obando, no quiso viajar más y su proceso de conciencia de ser indígena era real. Se puede decir que fue uno de los resultados de Colombia Solidaria aquí, nosotros hicimos el acompañamiento. A pesar de los conflictos locales podemos decir que el cabildo y la Cooperativa de Productores Lecheros de Obando (Coproleo) son las dos huellas de nuestra presencia aquí. (Amanda, reclutadora y directora de Colombia Solidaria, Obando, Nariño, mayo del 2013, diario de campo)

El estudio de caso nos muestra cómo estos grupos intentaron erigirse como una élite local, gracias a la gestión de relaciones diferenciadas y de patronazgo con las personas reclutadoras y jefes de la ONG. Este hecho nos remonta a la importancia de las diferencias de poder entre espacios y sitios en el campo social transnacional. Un ejemplo lo encontramos en el estudio de Katy Gardner (1995) para Bangladesh, del cual se desprende que las personas inmigrantes y los grupos vinculados a la migración experimentan una nueva mirada y comprensión del espacio-tiempo en estos procesos globales y locales: la movilidad y el control sobre la movilidad reflejan relaciones de poder diferenciadas. El hecho de que el control de un grupo "debilite" a los otros genera una incipiente diferenciación social y se puede observar en el caso expuesto. 


\section{Grupos domésticos transnacionales: ¿ascenso social y "mejoría de la vida" dentro de las normas de la circularidad?}

En el estudio de caso de Obando debemos adentrarnos en la esfera de los grupos domésticos, sus usos de las remesas y sus estrategias de reproducción social en la circularidad. Allí encontramos un escenario de significaciones en relación con el ascenso social y el mejoramiento de la vida, pero también en cómo se usa el estatus adquirido y se fusiona con aspectos materiales, productivos y reproductivos. Para ello debemos ubicarnos primero en las normas que subyacen a la circularidad laboral.

En este aspecto, la naturaleza jurídica y normativa de la migración circular condiciona las estrategias de reproducción social transnacional de las personas contratadas mediante este tipo de programas. Debemos recordar que la contratación en origen es una modalidad en la cual la persona trabajadora firma el contrato en su país de origen y se compromete al retorno una vez finalizada la temporada. La circularidad viene dada por la opción de ser contratada para la siguiente temporada, siempre que el empresario lo requiera de nuevo, que se haya registrado el retorno y que el Estado conceda el cupo. En este artículo partimos de la base de que la fórmula de suministro de mano de obra estudiada conlleva un control y el disciplinamiento, puesto que condiciona la relación social y laboral entre empresarios, trabajadores y organismos intermediarios al retorno y despoja a los trabajadores de sus derechos laborales, por la sujeción del contrato a la circularidad. Es decir, si la persona trabajadora desea seguir siendo contratada para la siguiente temporada, debe obedecer las normativas, evitar exigir derechos laborales, no ocasionar conflictos o permanecer en el régimen de circularidad. De este modo, el condicionante del retorno, la aceptación de la disciplina laboral y la posibilidad de ver el programa como la "puerta de entrada a Europa” permean constantemente las decisiones migratorias de los grupos domésticos transnacionales implicados. Se trata de la decisión de permanecer en el programa y regresar anualmente en origen o de instalarse en el país de destino y desertar del programa. Ambas opciones están presentes en la consecución de los proyectos de vida integrados por parte de los grupos estudiados en Obando y en sus usos de las remesas.

En un estudio cuantitativo y estadístico sobre el programa efectuado en el 2006 por Kraft y Larrard (2007), se pudo contrastar que los usos de los recursos obtenidos con la migración se empleaban con el punto de mira del proyecto 
migratorio en origen y, además, que el programa de la Unió de Pagesos generaba más inversión productiva que otras experiencias de contratación en origen. Sin embargo, el trabajo tiene sus matices. Los autores aplicaron una encuesta de 136 preguntas a 240 temporeros contratados en origen, en cuatro municipios de Colombia. Dos de estos municipios habían participado en el programa de la Unió de Pagesos y Colombia Solidaria y dos habían hecho parte de procesos de selección del Gobierno colombiano sin un programa de reinversión de las remesas. Los de los municipios del programa estudiado representaban el 34\% de participantes en el 2006 y se les preguntó por los usos de las remesas y su gestión, así como por los impactos en las relaciones de pareja, la integración y la participación y las expectativas. En el estudio se fijaron en dos indicadores de mejora: los proyectos productivos (bienes estables e ingresos derivados de estos) y los bienes durables (vivienda, muebles y electrodomésticos). Uno de los resultados obtenidos en el análisis econométrico de las regresiones fue que el programa de la UP generaba más inversión en proyectos productivos, pero que este factor era muy minoritario, puesto que cuanto más alto es el nivel total de remesas de una persona, existen más probabilidades de invertir y con un volumen mayor. Es decir, las personas contratadas en origen primero pagan sus deudas y mantienen el hogar antes de invertir en un proyecto productivo, ya que las inversiones son demasiado elevadas para el nivel de remesa que poseen. Esto significa que, a pesar de que los grupos domésticos con miembros contratados mediante la Unió de Pagesos invierten más, este fenómeno es muy limitado. Además, las principales inversiones que se contabilizan en el estudio de Kraft y Larrard son las de renovación o adquisición de vivienda ( $52 \%$ de las personas temporeras), las cuales son explicadas por la obligación del retorno que conlleva el programa. Por otro lado, en relación con la compra de tierra afirman que mientras un $13 \%$ de los temporeros eran dueños de un terreno antes de emigrar, el $23 \%$ tenían un terreno propio en el momento del estudio; pero en Nariño este porcentaje es más elevado: allí, un $40 \%$ de los temporeros tenían un terreno propio en el momento del estudio, en relación con el $25 \%$ antes de emigrar. Kraft y Larrard $(2007,49)$ indican que la variedad depende de la distribución, el precio de la tierra y la estructura de la propiedad. No obstante, precisan que un 45,9\% de los proyectos productivos iniciados eran poco rentables por la falta de acompañamiento y las dificultades de acceso al crédito.

Los hallazgos del material empírico del presente estudio se constatan y reafirman cuando se comparan con ejemplos paradigmáticos de otros programas de trabajadores temporales - el caso de México con el Programa Bracero (1965-1986) con Estados Unidos y el Programa de Trabajadores Agrícolas con Canadá (PTAT), iniciado en el 2004-. 
Por ejemplo, el trabajo de Tania Basok (2000) demuestra que la migración temporal mexicana hacia Ontario y sus efectos en origen se caracterizaron por el uso de las remesas en la mejora doméstica y la educación de los hijos, en detrimento de la inversión en actividades productivas. Según esta autora, los mejoramientos que experimentaron algunos hogares estaban altamente relacionados con los ingresos continuos externos de remesa. Esto significa que había patrones de asentamiento en destino por parte de las personas contratadas temporalmente. En relación con este hecho, Jorge Durand $(2007,100)$ indica que en estos programas los trabajadores acaban convirtiéndose en permanentes. En Alemania, por ejemplo, se concedieron extensiones de tiempo y muchos trabajadores terminaron quedándose y volviéndose indispensables. En este sentido, fueron las leyes y los empleadores quienes fomentaron que las personas contratadas cambiaran a trabajadoras definitivas, puesto que habían invertido en capacitarlas y era un desperdicio tener que despedirlas y enviarlas a su país de origen.

¿Qué obtenemos de estos dos estudios mencionados y qué relación presentan con los casos analizados aquí? Por un lado, que la capitalización de las remesas mediante negocios productivos individuales es baja, ya que las estrategias de reproducción social transnacional priorizan el consumo básico, la vivienda y la educación. Se debe permanecer muchos años en la circularidad, obedecer las normas laborales y mandar remesa permanentemente para que sea posible ahorrar lo necesario para realizar inversiones. Por otro lado, que otras experiencias en este tipo de programas derivaron en procesos de permanencia en los mercados laborales en destino. Estos aspectos se reflejan en algunos casos estudiados. Concretamente, en Obando se examinaron cuatro grupos domésticos. Los grupos 1 y 2 eran familiares entre sí y el 3 y el 4 eran socios de la ACNO desde un principio. Estos formaban parte de una minoría privilegiada en el municipio, puesto que su experiencia en la circularidad se dio a largo plazo — doce años-, en relación con las experiencias más generalizadas del resto de entrevistados que oscilaban entre dos y cinco temporadas.

El cabeza de hogar del grupo 1 formaba parte de la junta y el del grupo 2 era su hermano (junto con sus esposas, eran socios de la ACNO y los primeros en ser seleccionados en el 2001). Posteriormente, viajaron los hijos del primer grupo. Durante la tercera temporada decidieron quedarse en Catalunya, gracias a la posibilidad de acceder a sitios de trabajo permanentes que ofrecía uno de los empresarios para el que habían trabajado. En el 2012 estaban encargados de una cooperativa agrícola. Una vez instalados en el lugar de destino y hasta bien entrada la crisis económica en el Estado español (2008), intermediaron para contratar a familiares directos - por ejemplo, la mujer de su tío, del grupo 2-, así como a miembros de su grupo de afinidad. Hasta seis personas fueron movilizadas 
hacia el sitio donde trabajaban. Por su lado, el grupo 3 habitaba en el mismo vecindario rural que los grupos 1 y 2 y formaba una red de intercambio y ayuda mutua entre vecinos. También, se benefició de la estrategia de quedarse en destino e insertarse en la empresa con sus vecinos. El grupo 4, a pesar de ser socios de la ACNO, formaba parte del grupo que denunció a don Javier y a la junta de socios y vivía en la circularidad permanentemente.

En relación con la movilidad social y la diferenciación local, la experiencia de uno de estos grupos, así como la pertenencia de los tres primeros a una red social local, nos enfrenta a una incongruencia del programa. Durante la inmersión etnográfica se pudo observar cómo los miembros del grupo 1 se estaban convirtiendo en pequeños patronos con trabajadores en sus fincas. Además, junto con los grupos 2 y 3, gozaban del perfil de líderes comunitarios y formaban parte de los grupos de afinidad entre familias que intentaron tener acceso al poder local. Su caso tiene el poder de mostrarnos cómo, a diferencia de la gran mayoría de las personas reclutadas, ellos experimentan una particularidad: reciben remesas económicas constantemente. Esto significa que las personas de estos grupos domésticos que trabajan en Europa decidieron quedarse como inmigrantes permanentes y romper las trabas de retorno obligado del programa de contratación — “fugarse”- Dicho de otro modo: los grupos domésticos que han gozado de más movilidad geográfica y laboral en destino han experimentado procesos incipientes de movilidad social en origen, gracias al envío permanente de remesas y a su habilidad de usar el estatus adquirido y movilizar recursos sociales relacionados con la migración. A pesar de que el modelo MLTC estudiado tiene una tasa de deserción baja, del $6 \%$ (Kraft y Larrard 2007), y muchas de las personas contratadas cumplían con el compromiso de retorno, las personas instaladas en destino han alimentado un capital social migratorio, gracias a los usos del prestigio, la participación política local y la conexión con los empresarios agrícolas. En definitiva, de lo expuesto emergen dos elementos: primero, que la inversión productiva de la remesa es minoritaria; segundo, que antes de la crisis en el Estado español se estaban generando canales de migración permanente al margen del programa.

\section{Conclusiones. Los beneficios de la migración y la movilidad social: un reparto desigual}

Del análisis sobre los efectos y cambios del programa de contratación y codesarrollo implementado por la Unió de Pagesos podemos sacar varias conclusiones. 
La primera es que este entramado de intervenciones sobre poblaciones desfavorecidas se conecta con canales informales de reclutamiento y de gestión de los recursos a escala regional, local y transnacional. La segunda se refiere a cómo, en el campo social transnacional y en el lugar de origen mismo, los reclutadores construyen categorías de trabajadores aptas para ser movilizadas y en función de características observables como el género y la procedencia. La tercera alude a una paradoja: las personas que desertan del programa son quienes más capitalizan las remesas en su aspecto monetario y productivo, y también como recurso social; además, generan nuevas redes y capital social migratorio, pero constituyen una minoría en proceso de diferenciación social a escala local. Una cuarta y última conclusión nos muestra cómo se produce una distribución desigual de las ganancias de este proceso de migración laboral.

Por lo anterior, la investigación da luces sobre las asimetrías en el intercambio internacional de capital y trabajo. Se ha expuesto cómo, a pesar de los principios del programa, existe una desigualdad en el reparto de los beneficios de la migración a escalas global, institucional y local y se pone en tela de juicio el beneficio mutuo en los términos propuestos por la agencia de contratación y la política migratoria. Para el Estado español, este tipo de programas proporciona una mano de obra de movimiento controlado y externaliza los costes de asentamiento y reproducción sobre los países en origen y las personas inmóviles. Las empresas de la agroindustria obtienen mano de obra barata y fidelizada, justo al tiempo de la recolección, que retorna a su origen una vez finalizado el contrato. Los intermediarios obtienen un beneficio directo como empresarios de la migración en la gestión lucrativa de toda una serie de servicios que requiere el proceso. En el ámbito local, los agentes sociales como alcaldías, organizaciones y ONG aprovechan los recursos de la migración para afianzar posiciones y se convierten en actores activos en procesos económicos y sociales. Finalmente, para los grupos domésticos la migración se convierte en un recurso que permite el mejoramiento de la vida, bajo una lógica de reproducción social del grupo doméstico, pero no de maximización del beneficio y capitalización — con excepción de unos casos particulares-. La aceptación del sistema de explotación y tener miembros del grupo asalariados en mercados de trabajo segmentados a partir de la etnia y el género, con movilidad controlada, pero con salarios más altos, se combina con el trabajo invisibilizado de las personas inmóviles en este proceso - gran parte de ellas mujeres-, pero conectadas transnacionalmente en un mismo proyecto migratorio ${ }^{17}$. por motivos de extensión. Cabe destacar que existe una importante población femenina 
El caso etnográfico documentado nos muestra qué pasa con quienes están detrás de los que se mueven. Como señalada Levitt (1996), la gente, el dinero y las remesas sociales, entendidas como ideas, prácticas, identidades y capital social que se remite en origen, permean la vida cotidiana de quienes están atrás, producen transformaciones sociales, y las personas migrantes y las no migrantes ocupan el mismo espacio de intercambio - en conexión permanente-, a pesar de las leyes y el control constante de la movilidad. En el estudio presentado se afirma que este vínculo se produce en el momento en que se induce la migración mediante un programa, los procesos de selección y la entrada de agentes locales gestores del proceso como alcaldías, organizaciones sociales y familias, que interactúan con una estructura institucional migratoria. Si bien no se trata de una red migratoria, sí se corresponde con formas de relación locales, basadas en solidaridades familiares, reciprocidad y clientelismo, muy comunes en el mundo campesino, que se conectan y mantienen un canal con los mercados de trabajo en el agro catalán. Este tipo de conductas e instituciones extraeconómicas y no mercantilizadas se retroalimentan con la actividad de intermediación y en el momento de redistribuir los beneficios obtenidos con la migración. En este punto, el material empírico nos ha mostrado cómo se perfila una jerarquización basada en relaciones asimétricas entre personas pertenecientes a un mismo grupo local, pero también en relación con estos agentes reclutadores y sus empresas migratorias.

La experiencia se cristaliza en la formación de nuevos grupos de liderazgo local de corte clientelar, formados por individuos, grupos domésticos y líderes de asociaciones participantes de la experiencia migratoria, como temporeros o como gestores. Manejar los recursos sociales y económicos del proceso, así como acumular información, permite el cambio de estatus y da prestigio. Se genera una nueva relación de poder, fruto de distintas transferencias económicas, sociales y culturales durante el proceso migratorio de trece años de duración que, a su vez, posibilita acceder a más recursos materiales y sociales. De este modo, la reactivación de los fenómenos de clientelismo da cuenta de la importancia de analizar los factores extraeconómicos en las migraciones. La reciprocidad, las normas morales y la devolución de los favores son un elemento clave en las estrategias migratorias colectivas en este programa.

que permanece y gestiona las remesas en la reproducción social, especialmente, pensando en los hijos y el sustento del grupo familiar. También, es la que se encarga de los cuidados y los negocia constantemente en los proyectos migratorios transnacionales. Los usos de estos recursos, si bien no son productivos en el corto plazo y en un sentido estrictamente económico, sí tienen una lógica de mejoría y de ascenso social, sobre todo cuando se trata de la educación de los hijos. Además, se han documentado algunos casos de actividad productiva en las fincas o en pequeños negocios familiares informales de las mujeres que se quedan, gracias a las remesas migratorias. 
En definitiva, Obando nos muestra cómo se produce una significación local en plena conexión global: la experiencia de contratación en origen inducida por las personas empleadoras y su ONG hace viable el imaginario del sueño europeo, en un contexto de poblaciones abandonadas, empobrecidas, intervenidas y empujadas a moverse para rebuscarse la vida. Las personas que emigran cada año, las que se quedan en destino y los grupos domésticos que reciben remesas poseen el capital simbólico de la minoritaria y privilegiada experiencia de la movilidad transnacional. El cambio de estatus de unas pocas genera un efecto espejo sobre el resto. Bajo el telón de fondo de mejorar, salir de la pobreza, dignificar la vida o ascender socialmente, muchas personas aceptan el sistema de explotación laboral en destino y las privaciones en los derechos más básicos de movilidad.

\section{Referencias}

Achón, Olga. 2011. Importando miseria. La alternativa a la provisión de mano de obra agrícola. Madrid: Catarata.

Basok, Tania. 2000. "Migration of Migrant Seasonal Farm Workers to Canada and Development: Obstacles to Productive Investment”. International Migration Review 34 (1): 79-97.

Berlan, Jean Pierre. 1987. “La agricultura ‘mediterránea’ y el mercado de trabajo: ¿una California para Europa?”. Agricultura y Sociedad 42: 233-245.

Burawoy, Michael. 1976. "The Functions and the Reproduction of a Migrant Labor: Comparative Material from Southern Africa and the United States". American Journal of Sociology 81 (5): 1050-1087.

Cabezas Valencia, Rhina. 2011. “Migración circular laboral en España, el caso colombiano: impacto en las comunidades de origen”. En La migración latinoamericana en España: una mirada desde el modelo de acumulación de activos, coordinado por Jorge Ginieniewicz, 43-61. Quito: Flacso-GURG.

Durand, Jorge. 2007. Programas de trabajadores temporales. Evaluación y análisis del caso mexicano. Ciudad de México: Consejo Nacional de Población.

Fals Borda, Orlando. (1955) 1978. Campesinos de los Andes. Estudio sociológico de Saucío. Bogotá: Punta de Lanza.

Fundació Pagesos Solidaris. 2009. “Buenas prácticas en codesarrollo, 09”. Agencia Catalana de Cooperació al Desenvolupament. Consultado el 4 de enero del 2017. www.pagesossolidaris.org.

Fundación Agricultores Solidarios. 2010. “Memorias FAS 2009-2010”. Bogotá. Inédito.

Gardner, Katy. 1995. Global Migrants, Local Lives: Travel and Transformation in Rural Bangladesh. Oxford: Clarendon Press. 
Geronimi, Eduardo, Lorenzo Cachón y Ezequiel Teixidó. 2007. "Acuerdos bilaterales de migración de mano de obra: estudio de casos”. Estudios sobre Migraciones Internacionales 66. Ginebra: OIT.

Glick Schiller, Nina y Ayse Çaglar. 2008. "Migrant Incorporation and City Scale: Towards a Theory of Locality in Migration Studies". Willy Brandt Series of Working Papers in International Migration and Ethnic Relations 2/07 (Malmö Institute for Studies of Migration). http:// dspace.mah.se/bitstream/handle/2043/5935/WB_2_07_final.pdf?sequence=1\&isAllowed=y.

Goldring, Luin. 2002. "The Mexican State and Transmigrant Organizations: Negotiating the Boundaries of Membership and Participation”. Latin American Research Review 37: 55-99.

Gordo Márquez, Mercedes. 2008. "La contratación en origen de rumanos para actividades agrícolas de temporada en España”. Cuadernos de Geografía 84: 237-262.

Goss, Jon y Bruce Lindquist. 1995. “Conceptualizing Internacional Labor Migration: A Structuration Perspective”. Internacional Migration Review 29 (2): 317-351.

Hernández León, Rubén. 2012. "La industria de la migración en el sistema migratorio México-Estados Unidos”. Trace 61: 41-61. Consultado el 9 septiembre del 2014. http://trace. revues.org/1147.

Jabardo Velasco, Mercedes. 1999. "Migración clandestina y agricultura intensiva: la reestructuración del mercado de trabajo en el maresme catalán”. En Inmigrantes entre nosotros. Trabajo, cultura y educación intercultural, coordinado por Encarna Soriano y Francisco Checa y Olmos, 67-92. Barcelona: Icaria.

Kearney, Michael. 1996. "Del indigenismo a los derechos humanos. Etnicidad y política más allá de la mixteca”. Nueva Antropología 14 (46): 49-67.

Kraft, Robin y Marguerite de Larrard. 2007. “Codéveloppement \& mouvements internationaux de main d'œuvre: evaluation des programmes de migration temporaire et circulaire entre la Colombie et l'Espagne”. Tesis de Master d'Economie du Développement International, Sciences-Po, París.

Lacomba, Joan y Jesús Sanz Abad. 2013. "No es solo mandar dinero. Transferencias y remesas de los migrantes más allá de su dimensión económica”. Revista Migraciones 34: 45-76.

Levitt, Peggy. 1996. "Social Remittances: A Conceptual Tool for Understanding Migration and Development”. Working Paper 96 (04). http://citeseerx.ist.psu.edu/viewdoc/download;jses sionid=BA74A366998C0B36D81BDFF333AFF023?doi=10.1.1.196.2278\&rep=rep1\&type=pdf.

-. 2001. Transnational Villagers. Berkeley: University of California Press.

Martínez Veiga, Ubaldo. 2001. El ejido. Discriminación, exclusión social y racismo. Madrid: Catarata.

Mauss, Marcel. (1923-1924) 2002. "Essai sur le don. Forme et raison de l'échange dans les societés archaiques”. En L'Année Sociologique, segunda serie. Versión electrónica de JeanMarie Tremblay para Les classiques des sciences sociales. Consultado el 4 de enero del 2017. http://www.unige.ch/sciences-societe/socio/files/9114/0533/6019/Mauss_1923.pdf.

Mejía, William, Ana M. Murillo, Diana Martínez, Diana Ramírez, Érika Bedoya, Jackeline Mena, María C. Galvis, Maribel Restrepo y Yeim Castro. 2009. "La experiencia del 
modelo de contratación laboral temporal y circular de la Unión de Agricultores de Cataluña en Colombia, vista desde las comunidades de origen de los trabajadores”. En Migración laboral, temporal y circular: experiencias, retos y oportunidades. OIM, 128-149. Serie Investigaciones en Migración 2. Bogotá: Organización Mundial de las Migraciones.

Morelló, Núria. 2010. “Treballar i marxar. Agricultura globalitzada i sistemes de treball migratori”. Tesis de Maestría en Antropología, Universidad de Barcelona. http://diposit. ub.edu/dspace/bitstream/2445/49252/1/Treballar_marxar.pdf.

Morelló, Núria y Diana Sarkis. 2013. “¿Lazos de ayuda o patronazgo? La sostenibilidad de las nuevas economías agrícolas en la globalización: una comparación entre Catalunya y Siria”. En Economías cotidianas, economías sociales y economías sostenibles, editado por Susana Narotzky, 265-305. Barcelona: Icaria.

Narotzky, Susana. 2004. Antropología económica. Nuevas tendencias. Barcelona: Melusina.

Nyberg Sorensen, Nina. 2004. "Migrant Transfers as Development Tool: The Case of Morocco". DIIS Working Paper 2004: 17. Copenhagen: Danish Institute of International Studies. https: //www.files.ethz.ch/isn/18657/Migrant_Transfers_Development_Tool_Morocco.pdf.

Pedreño, Andrés. 2001. “Gitanos, magrebíes, ecuatorianos: una segmentación étnica del mercado de trabajo en el campo murciano (España)”. Ecuador Debate 54: 189-200.

-. 2007. "Proletarizados y etnificados: la inmigración ecuatoriana en la agricultura intensiva de la región de Murcia”. En Ciudadanía y exclusión: Ecuador y España frente al espejo, editado por Víctor Bretón, Francisco García, Antoni Jové y María José Vilalta, 225-250. Madrid: Los Libros de la Catarata.

Polanyi, Karl. (1957) 1964. "La economía como actividad institucionalizada”. En Comercio y mercado en los imperios antiguos, editado por Karl Polanyi, Conrad Arenseberg y Harry Pearson, 289-316. Barcelona: Labor.

Reigada, Alicia. 2009. "Las nuevas temporeras de la fresa en Huelva. Flexibilidad productiva, contratación en origen y feminización del trabajo en una agricultura globalizada”. Tesis doctoral inédita, Universidad de Sevilla.

Roll, David y Pablo Biderbost. 2009. "Evaluación de experiencias de contratación de trabajadores de origen inmigrante. Identificación de condiciones para la replicabilidad de la MLTC en España”. En Migración laboral, temporal y circular. Experiencias, retos y oportunidades, 91-127. OIM. Serie Investigaciones en Migración 2. Bogotá: Organización Mundial de las Migraciones.

Ruhs, Martin. 2006. “Potentiel des programmes de migration temporaire dans l'organisation des migrations internationales”. Revue Internationale du Travail 145: 7-41.

Sánchez, Elena y Raquel Faúndez. 2009. "Nuevas estrategias para el desarrollo desde la visión pública: una iniciativa empresarial privada”. Ponencia presentada en el IX Congreso Español de Ciencia Política y de la Administración: Repensar la Democracia: Inclusión y Diversidad. Departamento de Ciencia Política, Universitat Pompeu Fabra: Barcelona, Málaga. Septiembre.

Unió de Pagesos. 1999. “Memòria de temporers”. Informe prueba piloto para la contratación de trabajadores extranjeros en la agricultura. Melilla. Inédito. 
Vargas Meza, Ricardo. 2003. Drogas, conflicto armado y desarrollo alternativo. Una perspectiva desde el sur de Colombia. Bogotá: Acción Andina Colombia.

Vertovec, Steven y Robin Cohen, eds. 1999. Migrations, Diasporas and Transnationalism. Cheltenham: Edward Elgar.

Wolf, Eric. 1980. "Relaciones de parentesco, de amistad y de patronazgo en las sociedades complejas”. En Antropología social de las sociedades complejas, compilado por Michel Banton, 19-39. Madrid: Alianza.

Zapata Barrero, Ricard, Raquel Faúndez García y Elena Sánchez Montijano. 2009. “Migración laboral, temporal y circular (MLCT) de trabajadores entre Colombia y España. Un modelo a consolidar”. En Migración laboral, temporal y circular: experiencias, retos y oportunidades, 55-90. OIM. Serie Investigaciones en Migración 2. Bogotá: Organización Mundial de las Migraciones. 